\title{
AKTIVASI ZEOLIT SECARA FISIKA DAN KIMIA UNTUK MENURUNKAN KADAR KESADAHAN (Ca dan Mg) DALAM AIR TANAH
}

\section{(ACTIVATION OF ZEOLITE BY PHYSICAL AND CHEMICAL METHODS TO REDUCE THE HARDNESS (Ca and Mg) OF GROUNDWATER)}

\author{
Novi Nur Aidha \\ Balai Besar Kimia dan Kemasan, Kementerian Perindustrian \\ JI . Balai Kimia 1, Pekayon, Pasar Rebo, Jakarta Timur \\ E-mail : novi aidha@yahoo.com
}

Received : 19 Maret 2013 ; revised : 16 April 2013; accepted : 29 April 2013

\begin{abstract}
ABSTRAK
Zeolit merupakan bahan adsorber yang memiliki kemampuan untuk menyerap logam dalam air. Penelitian ini membandingkan daya adsorbsi zeolit alam yang berasal dari Malang dan Blitar untuk menurunkan kadar kesadahan air tanah. Zeolit diaktivasi terlebih dahulu sebelum digunakan, proses aktivasi yang dilakukan secara fisika dan kimia. Metode aktivasi secara fisika dilakukan dengan memperkecil ukuran partikel 80 mesh dan kalsinasi pada suhu $300^{\circ} \mathrm{C}$ selama $2 \mathrm{jam}$. Proses aktivasi secara kimia, zeolit direndam dalam pelarut asam yaitu $\mathrm{HCl}$ dengan variasi konsentrasi $0,1 \mathrm{~N} ; 0,25 \mathrm{~N} ; 0,5 \mathrm{~N} ; 0,75 \mathrm{~N}$; dan $1 \mathrm{~N}$ selama 80 menit. Setelah proses aktivasi, air tanah dialirkan melewati zeolit yang sudah dimasukkan dalam pipa kolom. Analisis kadar kesadahan (Mg dan $\mathrm{Ca}$ ) dilakukan sebelum air tanah dialirkan ke pipa kolom berisi zeolit dan sesudah dialirkan menggunakan alat Spektrofotometer Serapan Atom (SSA). Hasil penelitian menunjukkan bahwa konsentrasi HCI maksimal adalah $1 \%$ dengan persentase penurunan kadar $\mathrm{Ca}$ pada zeolit asal Blitar sebesar $78,99 \%$ dan zeolit asal Malang sebesar $68,49 \%$. Sedangkan persentase penurunan kadar Mg pada zeolit Blitar $49,91 \%$ dan pada zeolit Malang sebesar $42,13 \%$.
\end{abstract}

Kata kunci : Zeolit, Zeolit alam, Kesadahan, Aktivasi zeolit, Pertukaran ion

\begin{abstract}
Zeolite is an adsorbent material that has an ability to absorb metals in the water. In this study, comparison of the natural zeolite from Malang and Blitar after activation by physical and chemical methods for reducing hardness of groundwater was conducted. Activation method for physically treatment used for reduced the zeolite particle size to 80 mesh and calcined at temperature $300^{\circ} \mathrm{C}$ for 2 hours. The activation method for chemical treatment conducted by soaked the zeolite in an acidic solvent with various concentrations of $\mathrm{HCl} 0.1 \mathrm{~N}, 0.25 \mathrm{~N}, 0.5 \mathrm{~N}, 0.75$ $\mathrm{N}$, and $1 \mathrm{~N}$ for 80 minutes with frequently stirring. After the activation processess, groundwater was flowed through the activated zeolite that has been filled in the column pipe. Hardness analysis (calcium and magnesium) was done before and after the groundwater flowed into the pipe column contains activated zeolite by AAS. The results showed that the maximum concentration of $\mathrm{HCl} 1 \%$ with the percentage decrease in the calcium content $78.99 \%$ for zeolite from Blitar and $68.49 \%$ from Malang, while the percentage decrease in the magnesium content $49.91 \%$ for zeolite Blitar and $42.13 \%$ for zeolite Malang.
\end{abstract}

Key words : Zeolite, Natural zeolite, Hardness, Zeolite activation, lon exchanger

\section{PENDAHULUAN}

Air tanah pada umumnya memiliki tingkat kesadahan yang tinggi karena adanya kontak langsung dengan batuan kapur yang mengandung Kalsium (Ca) dan Magnesium $(\mathrm{Mg})$. Penghilangan kesadahan dengan proses pemanasan air tanah dapat membentuk garam yang tidak larut dan mengendap. Garam ini dapat berpengaruh terhadap kadar garam kalsium dalam urin sehingga menyebabkan penyakit batu saluran kemih (Izhar dan Darmoatmodjo 2007). Dampak kesehatan lain apabila kadar air sadah melebihi batas maksimum (500 $\mathrm{mg} / \mathrm{l})$ adalah penyumbatan pembuluh darah jantung (cardiovasculer deseasae) (Nurullita dkk 2010).

Air tanah juga digunakan dalam proses produksi di industri. Persyaratan kesadahan air pada proses industri untuk kesadahan $\mathrm{Ca}$ dan 
Mg harus nol karena dapat menimbulkan kerak pada sistem peralatan yang mengganggu proses pemanasan dan juga merusak peralatan (Marsidi 2001).

Syarat mutu bahan-bahan inorganik yang diperbolehkan pada air bersih sesuai Peraturan Menteri Kesehatan RI Nomor 907/MENKES/SK/VII/2002 tentang persyaratan kualitas air minum disajikan pada Tabel 1.

Permasalahan kesadahan air tanah dialami di daerah Surabaya. Surabaya merupakan daerah industri dan padat penduduk, disamping itu timbul berbagai masalah pencemaran air tanah. Berdasar Pantauan Dinas Pemda Jatim menurut Peraturan Pemerintah no 82 tentang Pengelolaan Kualias Air dan Pengendalian Pencemaran Air, saat ini kualitas air Surabaya semakin menurun dari kualitas I menjadi kualitas II. Di dalam peraturan tersebut kualitas air dibagi menjadi IV kelas, semakin tinggi kelasnya semakin buruk kualitas airnya. Penurunan kualitas ini disebabkan berbagai pencemaran dari limbah domestik atau rumah tangga $60 \%$, limbah industri $30 \%$ dan limbah pertanian $10 \%$. Berkurangnya jumlah air yang diproduksi dari sumber mata air juga menjadikan kualitas air menurun. Dari 117 mata air yang ada hanya tersisa 53 sumber, untuk itu penelitian ini menggunakan air tanah Surabaya (Redaksi Surabaya Kita 2010)

Salah satu bahan mineral alam yang sangat melimpah di Indonesia adalah zeolit. Zeolit umumnya didefinisikan sebagai kristal alumina silika yang berstruktur tiga dimensi, yang terbentuk dari tetrahedral alumina dan silika dengan rongga-rongga di dalam yang berisi ion-ion logam, biasanya alkali atau alkali tanah dan molekul air yang dapat bergerak bebas. Secara empiris, rumus molekul zeolit adalah Mx/n.(AIO2)x.(SiO2)y.xH2O (Marsidi 2001).

Zeolit digunakan sebagai adsorben karena memiliki struktur kristal alumina silika dengan rongga-rongga yang berisi ion-ion

Tabel 1. Bahan-bahan inorganik (yang kemungkinan dapat menimbulkan keluhan pada konsumen) (Permenkes 2002)

\begin{tabular}{|l|c|c|}
\hline \multicolumn{1}{|c|}{ Parameter } & Satuan & $\begin{array}{c}\text { Kadar Maksimum } \\
\text { yang diperbolehkan }\end{array}$ \\
\hline Ammonia & 2 & 3 \\
\hline Alumunium & $\mathrm{mg} / \mathrm{l}$ & 1.5 \\
\hline Klorida & $\mathrm{mg} / \mathrm{l}$ & 0.2 \\
\hline Copper & $\mathrm{mg} / \mathrm{l}$ & 250 \\
\hline Kesadahan & $\mathrm{mg} / \mathrm{l}$ & 1 \\
\hline Hidrogen sulfida & $\mathrm{mg} / \mathrm{l}$ & 500 \\
\hline Besi & $\mathrm{mg} / \mathrm{l}$ & 0.05 \\
\hline Mangan & $\mathrm{mg} / \mathrm{l}$ & 0.3 \\
\hline pH & $\mathrm{mg} / \mathrm{l}$ & 0.1 \\
\hline Sodium & $\mathrm{mg} / \mathrm{l}$ & $6,5-8,5$ \\
\hline Sulfate & $\mathrm{mg} / \mathrm{l}$ & 200 \\
\hline Total padatan terlarut & $\mathrm{mg} / \mathrm{l}$ & 250 \\
\hline Seng & $\mathrm{mg} / \mathrm{l}$ & 1000 \\
\hline
\end{tabular}

logam. Aktivitas zeolit alam cenderung rendah karena masih banyak pengotor, untuk itu perlu dilakukan aktivasi (Las dkk 2011).

Proses aktivasi zeolit dapat dilakukan dengan metode secara fisika dan kimia. Aktivasi secara fisika dapat dilakukan dengan cara memperkecil ukuran untuk memperluas permukaan dan pemanasan pada suhu tinggi. Aktivasi secara kimia dilakukan dengan penambahan asam yang mengakibatkan terjadinya pertukaran kation dengan $\mathrm{H}^{+}$(Lestari 2010). Proses pertukaran ion sering digunakan karena metode ini sangat sederhana, tidak menghasilkan limbah buangan padat dan dapat dilakukan proses regenerasi dengan cara aktivasi (Marsidi 2001).

Rahman dan Hartono melaporkan bahwa zeolit alam mampu menurunkan kadar logam pada air tanah dengan memperkecil ukuran butirannya menjadi $33 \mathrm{~mm}$ (Rahman dan Hartono 2004).

Suriawan dan Nindhia sebelumnya melaporkan bahwa penambahan asam sulfat akan memperbesar porositas sehingga keaktifan zeolit meningkat (Suriawan dan Nindhia 2010).

Berdasar penelitian Pardoyo dkk penambahan asam $\mathrm{HCl}$ dengan konsentrasi $4 \mathrm{M}$, $6 \mathrm{M}, 8 \mathrm{M}$, dan $10 \mathrm{M}$ pada zeolit yang ditambahkan ion $\mathrm{Ca}^{+} 700$ ppm, semakin tinggi konsentrasi $\mathrm{HCl}$ yang ditambahkan semakin tinggi pula daya adsorbsi zeolit. Pada penelitian tersebut sampel zeolit yang digunakan berasal dari Bayah, Kabupaten Lebak provinsi Banten (Pardoyo dkk 2009)

Tujuan penelitian ini adalah untuk mengetahui aktivasi zeolit dengan cara mengaktivasi zeolit alam dari Blitar dan Malang dengan cara fisika dan kimia dalam menurunkan kadar kesadahan ( $\mathrm{Ca}$ dan $\mathrm{Mg}$ ) pada air tanah dengan lokasi di Surabaya. Hasil penelittian ini diharapkan dapat memberikan informasi kepada masyarakat teknologi adsorbsi menggunakan zeolit.

\section{BAHAN DAN METODE}

\section{Bahan}

Bahan yang digunakan pada penelitian ini adalah zeolit yang berasal dari Malang Selatan dan Blitar, asam klorida $(\mathrm{HCl})$ dengan variasi konsentrasi $0,1 \mathrm{~N} ; 0,25 \mathrm{~N} ; 0,5 \mathrm{~N} ; 0,75 \mathrm{~N}$; dan $1 \mathrm{~N}$, serta akuades. Air tanah yang digunakan pada penelitian ini berasal dari Surabaya.

Peralatan yang digunakan antara lain instrumen AAS merk Shimadzu, neraca merk Mettler Toledo, oven merk Shimadzu, botol akuades, batang pengaduk, beaker glass, kertas $\mathrm{pH}$, ayakan, gelas arloji, pipet volume, karet penghisap 


\section{Metode Aktivasi Zeolit}

Metode aktivasi zeolit dilakukan dalam tiga tahapan. Tahapan pertama yaitu memperkecil ukuran butiran dengan cara menggerus zeolit alam dan mengayaknya dengan ayakan ukuran 80 mesh $(0.177 \mathrm{~mm})$.

Tahapan kedua adalah proses aktivasi secara kimia dilakukan dengan penambahan asam klorida $(\mathrm{HCl})$ dengan variasi konsentrasi konsentrasi $0,1 \mathrm{~N}, 0,25 \mathrm{~N}, 0,5 \mathrm{~N}, 0,75 \mathrm{~N}$ dan $1 \mathrm{~N}$ selama 80 menit sambil diaduk. Setelah itu dilakukan pencucian menggunakan akuades hingga $\mathrm{pH}$ netral

Tahapan ketiga dilakukan kalsinasi dalam oven pada suhu $300^{\circ} \mathrm{C}$ selama 2 jam. Setiadi dan Pertiwi melaporkan bahwa proses kalsinasi yang dilakukan pada zeolit alam asal Malang suhu yang digunakan adalah $300^{\circ} \mathrm{C}$ sampai $600^{\circ} \mathrm{C}$ cukup efektif dan tidak merusak struktur awal zeolit (Setiadi dan Pertiwi 2007)

\section{Proses Adsorbsi Kalsium dan Magnesium (Ca dan Mg)}

Gambar 1 adalah desain peralatan untuk proses adsorpsi untuk penelitian ini. Sampel air tanah dialirkan melalui pipa aliran (No. 4) dari tangki feed (No.1) masuk ke kolom adsorpsi (No. 5) dengan bantuan pompa dan membuka semua valve $3 \mathrm{~A}$ dan menutup valve $3 \mathrm{~B}$. Setelah melewati kolom adsorpsi (No. 5) air sampel akan keluar dan ditampung dalam penampung (No. 8) untuk dianalisa.

\section{Metode Analisa $\mathrm{Ca}$ dan Mg Menggunakan Spektrofotometer Serapan Atom (SSA)}

Metode analisa dengan menggunakan SSA, pertama yaitu memasang lampu SAA dengan lampu katoda $\mathrm{Ca}$ dan $\mathrm{Mg}$, kemudian menyalakan SSA dan mendiamkan selama 10 menit sampai 20 menit. Setelah itu mengatur tekanan udara, gas Asetilen, serta panjang gelombang, dimana untuk $\mathrm{Ca}$ adalah $422,7 \mathrm{~nm}$ dan $\mathrm{Mg}$ adalah 285,2 $\mathrm{nm}$. Lalu lampu pembakar dinyalakan untuk mendapatkan respon yang maksimum selanjutnya menghubungkan selang absorbansi dengan sampel dan membaca absorbansi yang tampak pada layar SSA. Setelah data absorbansi didapat dimasukkan pada persamaaan garis linear pada kurva Kalibrasi, sehingga diperoleh kadar $\mathrm{Ca}$ dan $\mathrm{Mg}$ dengan satuan $\mathrm{mg} / \mathrm{L}$.

\section{HASIL DAN PEMBAHASAN}

Zeolit mempunyai kemampuan untuk mengadsorbsi $\mathrm{Mg}$ dan $\mathrm{Ca}$ yang ada di air tanah. Daya adsorbsi zeolit dapat ditingkatkan dengan proses aktivasi. Pada penelitian ini tahapan aktivasi dilakukan dengan memperkecil ukuran partikel zeolit menjadi 80 mesh dengan tujuan untuk memperluas permukaan yang dapat meningkatkan keaktifan dari zeolit alam. Selanjutnya dilakukan aktivasi dengan penambahan asam yaitu $\mathrm{HCl}$ dengan variasi konsentrasi $0,1 \mathrm{~N} ; 0,25 \mathrm{~N} ; 0,5 \mathrm{~N} ; 0,75 \mathrm{~N}$; dan 1 $\mathrm{N}$ untuk mengamati pengaruh konsentrasi $\mathrm{HCl}$ terhadap penurunan kadar kesadahan dalam sampel air tanah. Penambahan asam mengakibatkan terjadinya pertukaran kation dengan $\mathrm{H}^{+}$sehingga memperbesar rongga dalam kerangka zeolit dan meningkatkan daya adsorbnya. Setelah dicuci dengan akuades, zeolit dikalsinasi pada suhu $300^{\circ} \mathrm{C}$.

Hasil analisa awal (air tanah sebelum perlakuan) menggunakan instrumen SSA diketahui kadar $\mathrm{Ca}$ air tanah yang berasal dari Surabaya adalah 141,41 mg/l dan Mg 40,65 $\mathrm{mg} / \mathrm{l}$ (Tabel 2).

Berdasarkan Tabel 2 dapat diketahui bahwa konsentrasi $\mathrm{HCl} 1 \mathrm{~N}$ dapat menurunkan persentase penurunan kadar $\mathrm{Ca}$ tertinggi yaitu sebesar 78,99\% untuk zeolit asal Blitar, sedangkan untuk zeolit asal Malang sebesar $68,49 \%$. Berdasarkan tersebut, maka dapat disimpulkan bahwa zeolit asal Blitar mempunyai daya adsorb terhadap Ca lebih tinggi dibanding dengan zeolit asal Malang.

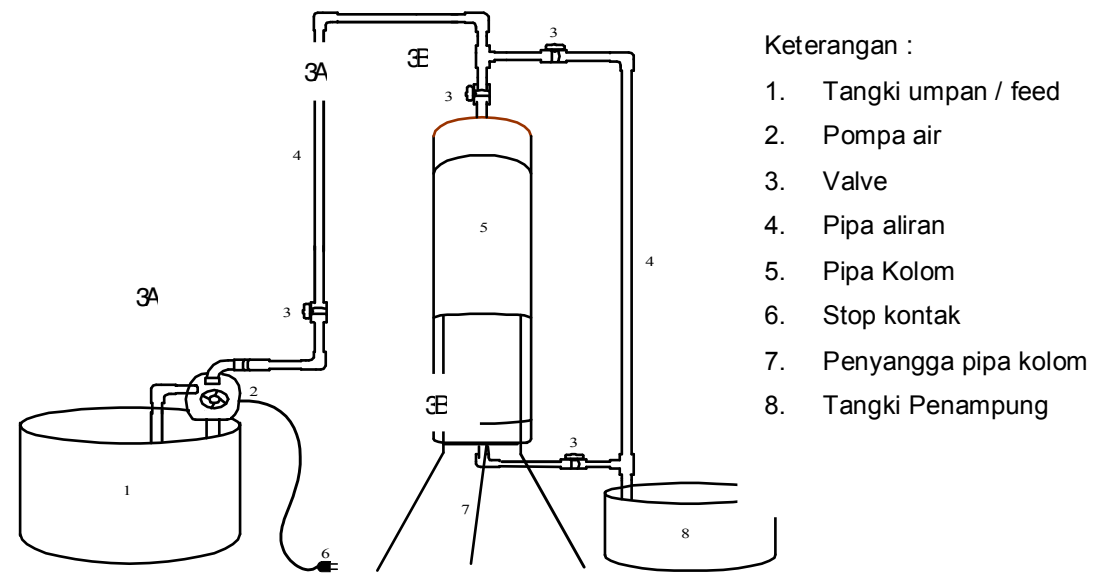

Gambar 1. Diagram peralatan penelitian 
Sedangkan untuk kadar Mg pada Tabel 3 menunjukkan bahwa konsentrasi $\mathrm{HCl} 1 \mathrm{~N}$ dapat menurunkan persentase penurunan kadar $\mathrm{Mg}$ tertinggi yaitu sebesar $49,91 \%$ untuk zeolit asal Blitar, sedangkan zeolit asal Malang sebesar $34,74 \%$. Tabel 2 dan 3 menunjukkan bahwa penambahan $\mathrm{HCl}$ sebesar $0.1 \%$ sudah dapat menurunkan kadar $\mathrm{Ca}$ dan $\mathrm{Mg}$. Ada kecenderungan bahwa semakin tinggi konsentrasi $\mathrm{HCl}$ maka semakin tinggi persentasi penurunan kadar $\mathrm{Ca}$ dan $\mathrm{Mg}$.

Tabel.2 Kadar Ca dan Mg dalam air tanah sebelum proses adsorbsi

\begin{tabular}{lc}
\hline \multicolumn{1}{c}{ Parameter } & Hasil $(\mathrm{mg} / \mathrm{l})$ \\
\hline Kalsium (Ca) & 141,41 \\
Magnesium (Mg) & 40,65 \\
\hline
\end{tabular}

Tabel.3 Persentase penurunan kadar Ca dengan variasi konsentrasi $\mathrm{HCl}$ pada zeolit Blitar dan Malang

\begin{tabular}{cccc}
\hline $\begin{array}{c}\text { Asal } \\
\text { Zeolite }\end{array}$ & $\begin{array}{c}\text { Konsentrasi } \\
\mathrm{HCl} \\
(\mathrm{N})\end{array}$ & $\begin{array}{c}\left.\text { Kadar }{ }_{*}\right) \\
(\mathrm{mg} / \mathrm{l})\end{array}$ & $\begin{array}{c}\text { Persentase } \\
\text { Penurunan Ca } \\
(\%)\end{array}$ \\
\hline \multirow{5}{*}{ Blitar } & 1,00 & 29,70 & 78,99 \\
& 0,75 & 31,07 & 78,03 \\
& 0,50 & 34,89 & 75,32 \\
& 0,25 & 38,62 & 72,69 \\
& 0,10 & 40,64 & 71,26 \\
\hline \multirow{5}{*}{ Malang } & 1,00 & 44,55 & 68,49 \\
& 0,75 & 45,42 & 67,88 \\
& 0,50 & 49,21 & 65,20 \\
& 0,25 & 52,75 & 62,70 \\
& 0,10 & 54,86 & 61,20 \\
\hline
\end{tabular}

Keterangan : *) Kadar Ca akhir : kadar Ca dalam air tanah setelah proses filtrasi dengan menggunakan zeolit Aktivasi fisik : memperkecil ukuran butiran mesh $80(0,177 \mathrm{~mm})$ dan kalsinasi $300^{\circ} \mathrm{C}$

Tabel 4. Persentase penurunan kadar Mg dengan variasi konsentrasi $\mathrm{HCl}$ pada zeolit Blitar Dan Malang

\begin{tabular}{cccc}
\hline $\begin{array}{c}\text { Asal } \\
\text { Zeolite }\end{array}$ & $\begin{array}{c}\text { Konsentrasi } \\
\mathrm{HCl}(\mathrm{N})\end{array}$ & $\begin{array}{c}\text { Kadar Mg } \\
\left.\text { Akhir }{ }^{*}\right) \\
(\mathrm{mg} / \mathrm{l})\end{array}$ & $\begin{array}{c}\text { Persentase } \\
\text { Penurunan Mg } \\
(\%)\end{array}$ \\
\hline \multirow{5}{*}{ Blitar } & 1 & 20,36 & 49,91 \\
& 0,75 & 22,76 & 44,12 \\
& 0,5 & 25,14 & 38,13 \\
Malang & 0,25 & 25,97 & 36,09 \\
Malang & 0,1 & 28,32 & 30,33 \\
\hline & 0,75 & 26,52 & 34,74 \\
& 0,5 & 24,83 & 38,90 \\
& 0,25 & 29,69 & 26,95 \\
& 0,1 & 31,51 & 22,47 \\
\hline
\end{tabular}

Keterangan : *) Kadar Mg Akhir : Kadar Mg dalam air tanah setelah proses filtrasi dengan menggunakan zeolit Aktivasi fisik : memperkecil ukuran butiran mesh $80(0,177 \mathrm{~mm})$ dan kalsinasi $300^{\circ} \mathrm{C}$. 
Berdasar syarat mutu Peraturan Menteri Kesehatan RI Nomor 907/MENKES/SK/VII/2002 tentang persyaratan kualitas air minum, kadar $\mathrm{Ca}$ dan $\mathrm{Mg}$ awal yang diperoleh sudah memenuhi baku mutu yaitu tidak melebihi 500 $\mathrm{mg} / \mathrm{l}$. Hal ini dikarenakan sampel air yang diambil adalah air PDAM yang sebelumnya sudah melalui perlakuan terlebih dahulu. Penelitian ini hanya untuk mengetahui pesentase penurunan kadar $\mathrm{Ca}$ dan $\mathrm{Mg}$ setelah perlakuan menggunakan zeolit alam yang sudah diaktivasi

Konsentrasi optimum $\mathrm{HCl}$ belum didapatkan untuk penurunan kadar $\mathrm{Ca}$ dan $\mathrm{Mg}$ secara maksimal.

Rahman dan Hartono melaporkan bahwa zeolit alam mampu menurunkan kadar logam air tanah dengan memperkecil ukuran butirannya menjadi $33 \mathrm{~mm}$. Sedangkan pada penelitian ini ukuran butiran zeolit diperkecil menjadi 80 mesh $(0,177 \mathrm{~mm})$. Ukuran ini lebih memperluas permukaan zeolit sehingga daya adsorbsi zeolit lebih meningkat.

Kandungan logam $\mathrm{Ca}$ dan Mg mengalami penurunan karena mengalami pertukaran ion antara kation-kation dari zeolit dengan proton dari $\mathrm{HCl}$. Mekanisme adsorpsi yang terjadi antara ion $\mathrm{Ca}^{2+}$ dan $\mathrm{Mg}^{2+}$ dalam zeolit yaitu air sadah yang mengalir dalam kolom melewati zeolit akan dengan ion $\mathrm{H}^{+}$yang ada dalam rongga zeolit. Pertukaran ion tersebut terjadi secara terus menerus sampai kation yang ada dalam zeolit habis atau dengan kata lain zeolit mengalami kejenuhan (Lestari 2010). Pada penelitian Marsidi 2001, regenerasi zeolit menggunakan $\mathrm{NaCl}$, sedangkan pada penelitian ini menggunakan $\mathrm{HCl}$, sehingga mekanisme reaksi yang terjadi adalah sebagai berikut:

$\mathrm{H}_{2} \mathrm{Z}+\mathrm{Ca} \longrightarrow \mathrm{CaZ}+2 \mathrm{H}^{+}$

$\mathrm{H}_{2} \mathrm{Z}+\mathrm{Mg} \longrightarrow \mathrm{MgZ}+2 \mathrm{H}^{+}$

Sedangkan mekanisme reaksi regenerasi zeolit adalah sebagai berikut:

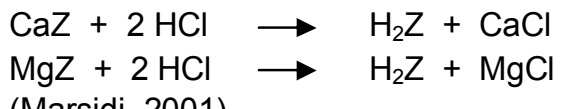

(Marsidi, 2001)

Suriawan dan Nindhia sebelumnya melaporkan bahwa penambahan asam sulfat akan memperbesar porositas sehingga keaktifan zeolit meningkat (Suriawan dan Nindhia 2010) Sedangkan pada penelitian ini digunakan asam klorida yang sifat kekuatan asamnya lebih rendah dari $\mathrm{H}_{2} \mathrm{SO}_{4}$. Penggunaan asam $\mathrm{HCl}$ lebih aman bagi lingkungan dan lebih murah.
Berdasar penelitian Pardoyo dkk, penambahan asam $\mathrm{HCl}$ dengan konsentrasi $4 \mathrm{M}$, $6 \mathrm{M}, 8 \mathrm{M}$, dan $10 \mathrm{M}$ pada zeolit yang ditambahkan ion $\mathrm{Ca}^{+} 700$ ppm, dapat meningkatkan daya adsorbsi zeolit dengan kecenderungan semakin tinggi konsentrasi $\mathrm{HCl}$ yang ditambahkan semakin tinggi pula daya adsorbsinya (Pardoyo dkk 2009). Sedangkan pada penelitian ini aktivasi secara kimia menggunakan $\mathrm{HCl}$ dengan variasi konsentrasi $0,1 \mathrm{~N} ; 0,25 \mathrm{~N} ; 0,5 \mathrm{~N} ; 0,75 \mathrm{~N}$; dan $1 \mathrm{~N}$ sudah dapat menurunkan kadar $\mathrm{Ca}$ dan Mg pada air tanah sebesar $61.33 \%$ sampai $78.99 \%$ untuk Ca dan $21,21 \%$ sampai $49,91 \%$ Mg. Hal ini membuktikan bahwa konsentrasi asam rendah, sudah dapat menurunkan kesadahan air jika proses aktivasi zeolit dikombinasi dengan aktivasi secara fisika.

Hasil penelitian ini menunjukkan pula bahwa zeolit yang berasal dari Blitar mempunyai kemampuan yang lebih besar dibanding zeolit Malang dalam menurunkan kadar kesadahan $\mathrm{Ca}$ dan Mg yang terdapat pada air tanah. Perbedaan daya serap kesadahan $\mathrm{Ca}$ dan $\mathrm{Mg}$ asal Blitar dan Malang karena struktur zeolit berbeda. Berdasar penelitian yang telah dilakukan oleh Muhaji dan Mulyani, jenis mineral dan komposisi kimia zeolit asal Malang dan Blitar berbeda. Zeolit Malang merupakan mineral mordenit dan zeolit Blitar merupakan mineral klinoptilotit dengan perbedaan komposisi kimianya disajikan pada Tabel 5 (Muhaji dan Mulyani 2007).

Tabel 5. Jenis mineral zeolit dan komposisi kimia zeolit asal Malang dan Blitar.

\begin{tabular}{|c|c|c|}
\hline Asal Zeolit & Malang & Blitar \\
\hline Jenis Mineral & $\begin{array}{l}\text { Modernit } \\
\mathrm{Na}_{8}\left(\mathrm{Al}_{8} \mathrm{Si}_{40} \mathrm{O}_{96}\right) 24 \\
\mathrm{H}_{2} \mathrm{O}\end{array}$ & $\begin{array}{l}\text { Klinoptilotit } \\
\mathrm{Na}_{4} \mathrm{~K}_{4}\left(\mathrm{Al}_{8} \mathrm{Si}_{40} \mathrm{O}_{96}\right) \\
24 \mathrm{H}_{2} \mathrm{O}\end{array}$ \\
\hline \multicolumn{3}{|c|}{$\begin{array}{c}\text { Komposisi Kimia } \\
(\%)\end{array}$} \\
\hline & Malang & Blitar \\
\hline Silika $\left(\mathrm{SiO}_{2}\right)$ & 75,95 & 76,67 \\
\hline Alumina $\left(\mathrm{Al}_{2} \mathrm{O}_{3}\right)$ & 12,45 & 13,58 \\
\hline $\begin{array}{ll}\text { Besi } & \text { oksida } \\
\left(\mathrm{Fe}_{2} \mathrm{O}_{3}\right) & \\
\end{array}$ & 0,15 & 0,16 \\
\hline $\begin{array}{l}\text { Kalsium oksida } \\
(\mathrm{CaO})\end{array}$ & 3,11 & 2,08 \\
\hline $\begin{array}{l}\text { Magnesium } \\
\text { oksida (MgO) }\end{array}$ & 0,48 & 0,45 \\
\hline $\begin{array}{ll}\begin{array}{l}\text { Titan } \\
\left(\mathrm{TiO}_{2}\right)\end{array} & \text { oksida } \\
\end{array}$ & 1,20 & 2,23 \\
\hline $\begin{array}{l}\text { Natrium oksida } \\
\left(\mathrm{Na}_{2} \mathrm{O}\right)\end{array}$ & 1,12 & 1,10 \\
\hline $\begin{array}{l}\text { Kalium oksida } \\
\left(\mathrm{K}_{2} \mathrm{O}\right)\end{array}$ & 0,07 & 1,09 \\
\hline Kadar air $\left(\mathrm{H}_{2} \mathrm{O}\right)$ & 5,46 & 5,49 \\
\hline
\end{tabular}


Perbedaan komposisi antara zeolit Malang dan Blitar disebabkan karena letak geologis kedua zeolit tersebut berbeda.dengan kondisi lingkungan yang berbeda. Hal ini berpengaruh terhadap proses pembentukan zeolit dan kandungan mineral di dalamnya yaitu perbandingan unsur Si/Al atau silika/alumino sebagai unsur pembangun utama struktur kerangka zeolit. Sifat dari masing-masing zeolit ditentukan dari unsur utama dari zeolit (Setiawan 2006).

Hal ini diperkuat oleh Lestari dan Yuanita yang menyatakan bahwa zeolit dengan kadar silika tinggi akan stabil pada suhu tinggi bersifat hidrofobik (dan lipofilik), lebih stabil pada suhu tinggi dan lebih stabil pada kondisi asam kuat, sedangkan zeolit dengan kadar silika rendah lebih stabil pada suhu rendah, bersifat hidrofobik dan mudah rusak pada $\mathrm{pH}$ kurang dari 4 (Lestari 2010)

Hasil penelitian secara keseluruhan menunjukkan bahwa penelitian lebih lanjut masih diperlukan dengan menambahkan variabel konsentrasi $\mathrm{HCl}$ yang dibuat diatas $1 \mathrm{~N}$ sampai didapatkan konsentrasi yang optimum. Selain itu, penelitian dengan memberikan perlakuan lama waktu perendaman seharusnya perlu juga dibuat variasinya untuk mendapatkan waktu perendamaan $\mathrm{HCl}$ yang optimum termasuk penelitian lainnya seperti jenis ukuran butiran zeolit, waktu, kecepatan alir dan penggunaan zeolit yang berasal dari daerah lainnya yang mempunyai struktur yang berbeda dengan zeolit Blitar maupun zeolit Malang.

\section{KESIMPULAN}

Hasil penelitian ini menunjukkan bahwa pada proses aktivasi zeolit gabungan metode fisika dan kimia dapat meningkatkan penurunan kadar kesadahan pada air tanah. Semakin meningkatnya kadar $\mathrm{HCl}$ yang digunakan semakin tinggi daya absorbs zeolit terhadap $\mathrm{Ca}$ dan Mg. Selain itu, hasil penelitian ini juga menunjukkan bahwa persentase penurunan kadar $\mathrm{Ca}$ dan $\mathrm{Mg}$ tertinggi didapat pada konsentrasi $\mathrm{HCl}$ sebesar $1 \mathrm{~N}$ baik pada zeolit asal Blitar dan Malang. Penelitian lebih lanjut masih diperlukan dengan menambahkan konsentrasi $\mathrm{HCl}$ di atas $1 \mathrm{~N}$ agar diketahuinya konsentrasi optimal penggunaan zeolit untuk menurunkan kadar $\mathrm{Ca}$ dan $\mathrm{Mg}$.

\section{UCAPAN TERIMAKASIH}

Ucapan terimakasih disampaikan kepada teman-teman yang turut serta dalam penelitian ini, kepada Iwan Setiawan dan Haryanto selaku tim yang membantu di lapangan. Penulis juga mengucapkan terimakasih kepada Dr. Puspita Lisdiyanti, M.Chem, atas saran dan bimbingan dalam menyelesaikan penulisan ini.

\section{DAFTAR PUSTAKA}

Izhar, M Dody, K, Haripurnomo K, dan S. Darmoatmodjo. 2007. Hubungan Antara Kesadahan Air Minum, Kadar Kalsium dan

Sedimen Kalsium Oksalat Urin. Berita Kedokteran Masyarakat 23(4):200209.'

Las, T., F. Firdiyono, dan A. Hendrawan. 2011. Adsorpsi Unsur Pengotor Larutan Natrium Silikat Menggunakan Zeolit Alam Karangnunggal. Valensi 2(2): 368-378.

Lestari, Dewi Yuanita. 2010. Kajian Modifikasi Dan Karakterisasi Zeolit Alam Dari Berbagai Negara. Prosiding seminar Nasional Kimia dan pendidikan, Tema: "Profesionalisme Peneliti dan Pendidik dalam Riset dan Pembelajaran yang Berkualitas dan Berkarakter", Universitas Yogyakarta, 30 Oktober 2010

Marsidi, R. 2001. Zeolit Untuk Mengurangi Kesadahan Air. Jurnal Teknologi Lingkungan 2(1): 1-10.

Muhaji dan Mulyani, 2007. Pengaruh Proses Pembentukan Endapan Batuan Terhadap Kualitas Zeolit Alam, Fakultas Teknik, Universitas Negeri Surabaya. Surabaya.

Nurullita, U., A. Rahayu, dan M. Z. Arifin. 2010. Pengaruh Lama Kontak Karbon Aktif Sebagai Media Filter Terhadap Persentase Penurunan Kesadahan CaCO3 Air Sumur Artesis. Jurnal Kesehatan Masyarakat Indonesia 6: 48-56.

Pardoyo, L. dan A. Darmawan. 2009. Pengaruh Perlakuan $\mathrm{HCl}$ Pada Kristalinitas Dan Kemampuan Adsorbsi Zeolit Alam Terhadap Ion $\mathrm{Ca}^{+}$. Jurnal Sains dan Matematika (JSM) 17(2): 100-104.

Rahman, A. dan B. Hartono. 2004. Penyaringan Air Tanah Dengan Zeolit Alami Untuk Menurunkan Kadar Besi dan Mangan. Makara Kesehatan 8(1): 1-6.

Redaksi Surabayakita, Akibat Limbah, Kualitas Air Kali Menurun, 28 Juli 2010, 07:21. (http://www.surabayakita.com/index.ph p/option=com content\&view=article\&id =742:akibat-limbah-kualitas-air-kalisurabaya-turun-kelas, diakses 7 Mei 2013)

Republik Indonesia, 2002. Peraturan Menteri Kesehatan Nomor. 907/MEK/VII/2002 tentang Peryaratan Kualitas air Minum.

Setiadi, dan Astri Pertiwi. 2007 Preparasi dan Karakterisasi Zeolit Alam Untuk Konversi Senyawa ABE Menjadi Hidrokarbon. Prosiding Konggres Dan 
Simposium Nasional Kedua MKICS :

1-6.

Setiawan, D. 2006. Karakterisasi Beberapa Zeolit Alam Dalam Kaitannya Dengan Penyerapan Radionuklida Cesium ${ }^{134}$ $\left({ }^{134} \mathrm{Cs}\right)$.Jurnal Bionatura. 8(2):122-138

Suriawan, M. C. Vahindra, dan T. G. T. Nindhia. 2010. Studi Hubungan Struktur Mikro dan Keaktifan Zeolit Alam Akibat Proses Pengasaman. Jurnal IImiah Teknik Mesin CakraM 4(2): 129-131. 